\title{
Design and evaluation of sustained release spherical agglomerates of Fluvastatin sodium by crystallo-co-agglomeration
}

\author{
Dushyant Shah ${ }^{\mathrm{a}}$, Kishorkumar Sorathia ${ }^{\mathrm{b}}$ * \\ ${ }^{a}$ APMC College of Pharmaceutical Education and Research, Himmatnagar, Gujarat, India. \\ ${ }^{\mathrm{b}}$ Smt. C. V. Gajera Pharmacy Mahila College, Amreli, Gujarat, India.
}

\begin{tabular}{|c|c|}
\hline ARTICLE INFO & ABSTRACT \\
\hline Article history: & \multirow{11}{*}{$\begin{array}{l}\text { Prime objective of present study was to design and evaluate ready to compress sustained release spherical } \\
\text { agglomerates of Fluvastatin sodium. Crystallo-co-agglomeration technique of spherical crystallization utilizing } \\
\text { acetone-acetonitrile system was used to prepare spherical agglomerates of drug in presence of Eudragit RS100 } \\
\text { and RL100 as release retardant polymers. Prepared agglomerates were subjected for evaluation of flow, packing, } \\
\text { mechanical, compaction properties as well as in-vitro dissolution study. Morphology of spherical agglomerates } \\
\text { was evaluated by SEM and drug-polymer compatibility was carried out by DSC, FTIR and XRD. Matrix beads } \\
\text { were generated having uniform dispersion of drug with enhanced flow, packing, compaction and mechanical } \\
\text { properties which can be attributed to spherical shape of agglomerates as revealed in SEM photomicrographs. } \\
\text { Higher crushing strength of agglomerates was indication of good mechanical strength. Improved compressibility } \\
\text { of agglomerates was indicated by lower values of } \sigma_{0} \text {, improved tensile strength and reduced elastic recovery. } \\
\text { DSC, FTIR and XRD showed that drug did not undergo structural or polymorphic alterations in presence of } \\
\text { polymers. In-vitro dissolution study suggested utilization of process for sustained release of fluvastatin sodium } \\
\text { for sufficiently prolonged period of time depending on polymer concentration. Thus, crystallo-co-agglomeration } \\
\text { method can be successfully utilized for development of directly compressible sustained release agglomerates. }\end{array}$} \\
\hline Received on: 04/08/2017 & \\
\hline Accepted on: 16/09/207 & \\
\hline Available online: $30 / 09 / 2017$ & \\
\hline Key words: & \\
\hline Crystallo-co-agglomeration; & \\
\hline direct compression; & \\
\hline Fluvastatin sodium; spherical & \\
\hline crystallization, sustained & \\
\hline & \\
\hline & \\
\hline
\end{tabular}

\section{INTRODUCTION}

Sustained release dosage forms offer consistent therapeutically effective concentration in the systemic circulation for prolonged duration of time and maintain homogeneous therapeutic effect, which improve patient compliance (Chien and Lin, 2006). Controlled drug delivery can be obtained by judicious combination of natural or synthetic polymer with a drug in such a way that it releases drug in a predetermined manner. Drugs with shorter biological half life and low bioavailability require to be formulated as sustained release dosage forms to reduce dosing frequency and improve bioavailability.

\footnotetext{
* Corresponding Author

Kishorkumar Sorathia, Department of Pharmaceutics, Smt. C. V. Gajera Pharmacy Mahila College, Chakkargadh Road, Amreli-365601, Gujarat, India.Ph. +91 9426376056; E-mail: kishor_patel143 @ yahoo.co.in
}

Amongst various techniques available, spherical crystallization has gained more attention in the preparation of sustained release microparticles.

The technique is advantageous as it formulate microparticles with desired characteristics which can be employed as a directly compressible material (Maghsoodi and Yari, 2015). The technique can also be modified to a simple, consistent and economical method for the preparations of spherical matrices for sustained release of drugs. Sustained release spherical agglomerates of various drugs (Mahajan et al., 2009; Ozyazici et al., 2012) were prepared using spherical crystallization in combination of various polymers to prepare drug devices with prolonged drug release and improved bioavailability. Crystallo-coagglomeration is a amendment of spherical agglomeration technique devised to surmount the restrictions of spherical agglomeration to produce directly compressible agglomerates of poorly compressible drug(s) in combination with diluents (Kadam et al., 1997; Pawar et al., 2004; Jadhav et al., 2007). 
Using CCA with proper selection of excipients/polymers, drug release can also be modified from drug loaded agglomerates or compacts of agglomerates (Jadhav et al., 2010; Gadekar et al., 2011). CCA technique involves simultaneous crystallization and agglomeration of drug particles with or without excipients from good solvent and bridging liquid by addition of a poor solvent. Sometimes, good solvent also serves as bridging liquid. Presence of suitable excipient greatly affects the properties of agglomerates (Garala et al., 2012; Raval et al., 2013). Utilization of CCA in designing spherical agglomerates having excellent micromeritic and compression properties with satisfactory mechanical strength has been revealed in various studies. The technique has been successfully utilized for improving processability via enhancement in flow, compaction and packing properties (Maghsoodi et al., 2007; Maghsoodi and Tajalli Bakhsh, 2011). So far the technique has been applied for preparation of directly compressible sustained release agglomerates by few scientists (Jadhav et al., 2010; Gadekar et al., 2011); it is further required to study successful utilization of technique for the same. The present study was designed to employ crystallo-co-agglomeration in the preparation of sustained release spherical agglomerates in combination with polymer.

Fluvastatin sodium ((3S,5R,6E)-7-[3-(4-fluorophenyl)-1(propan-2-yl)-1H-indol-2-yl]-3,5-dihydroxyhept-6-enoic acid monosodium salt), is the first-generation statin of synthetic origin, used as antihyperlipidemic drug. It is a potent inhibitor of hydroxymethylglutaryl coenzyme A (HMG-CoA) reductase, the rate limiting enzyme in cholesterol biosynthesis. The drug has low bioavailability due to extensive first pass metabolism in the liver, less GI residence time and relatively short half life (1.2 hours) and so requires frequent dosing if formulated in the forms of conventional dosage form (Williams and Lemke, 2002). Many attempts have been made to develop sustained release preparation with extended clinical effects and reduce dosing frequency (Venkatesh et al., 2012; Gupta et al., 2014; Saini and Saini, 2016). The objectives of this study were to prepare directly compressible sustained release spherical agglomerates containing Fluvastatin Sodium by crystallo-co-agglomeration and to evaluate the prepared agglomerates for micromeritic, mechanical and compression properties and dissolution behavior.

\section{MATERIALS AND METHODS}

\section{Materials}

Fluvastatin sodium was procured from Suven Life Sciences Ltd., Hyderabad, India. Eudragit RS100 and Eudragit RL100 were procured from Corel Pharma-Chem, Ahmedabad, India. Acetone and acetonitrile were purchased from Merck Pvt. Ltd., Mumbai, India. All other solvents and chemicals used were of analytical grade (Loba Chemie Pvt. Ltd., Mumbai, India).

\section{Preparation of agglomerates}

Microparticles of Fluvastatin sodium were prepared by crystallo-co-agglomeration employing two solvent system i.e. good solvent and poor solvent. Acetone and acetonitrile were selected as good solvent and poor solvent respectively. Acetone also works as a bridging liquid. A procedure was designed where the drug (3 g) and polymer (1-3 g) were dissolved in acetone and added to the poor solvent (acetonitrile). The mixture was stirred continuously at the rate of about 350 RPM using magnetic stirrer. The stirring was persistent for about 3 hours. Crystallization of drug due to antisolvent effect of poor solvent and agglomeration of crystallized drug in presence of bridging liquid resulted into formation of spherically agglomerated microparticles. Finally the co-precipitated agglomerates of the drug-polymer were filtered and dried in desiccators at ambient temperature. Various types and concentration of polymers, as shown in Table 1, were used and optimized for good agglomeration.

Table 1: Formulation of agglomerates.

\begin{tabular}{cccccc}
\hline $\begin{array}{c}\text { Batch } \\
\text { Code }\end{array}$ & Polymer type & $\begin{array}{c}\text { Drug } \\
(\mathbf{g})\end{array}$ & $\begin{array}{c}\text { Polymer } \\
(\mathbf{g})\end{array}$ & $\begin{array}{c}\text { Polymer: } \\
\text { Drug } \\
\text { Ratio }\end{array}$ & $\begin{array}{c}\text { Polymer } \\
\%\end{array}$ \\
\hline ES1 & Eudragit RS100 & 3.0 & 1.0 & $1: 3$ & 25.00 \\
ES2 & Eudragit RS100 & 3.0 & 1.2 & $1: 2.5$ & 28.57 \\
ES3 & Eudragit RS100 & 3.0 & 1.5 & $1: 2$ & 33.33 \\
ES4 & Eudragit RS100 & 3.0 & 2.0 & $1: 1.5$ & 40.00 \\
ES5 & Eudragit RS100 & 3.0 & 3.0 & $1: 1$ & 50.00 \\
EL1 & Eudragit RL100 & 3.0 & 1.0 & $1: 3$ & 25.00 \\
EL2 & Eudragit RL100 & 3.0 & 1.2 & $1: 2.5$ & 28.57 \\
EL3 & Eudragit RL100 & 3.0 & 1.5 & $1: 2$ & 33.33 \\
EL4 & Eudragit RL100 & 3.0 & 2.0 & $1: 1.5$ & 40.00 \\
EL5 & Eudragit RL100 & 3.0 & 3.0 & $1: 1$ & 50.00 \\
\hline
\end{tabular}

\section{Loading efficiency and yield of agglomerates}

Loading efficiency, expressed as percentage (\%), is the ratio of experimentally calculated drug content to the theoretical value.

Experimental drug content was determined by dissolving $50 \mathrm{mg}$ of agglomerates into $50 \mathrm{ml}$ of $0.1 \mathrm{~N}$ sodium hydroxide solution in a volumetric flask and diluted $5 \mathrm{ml}$ of resulting solution to $100 \mathrm{ml}$ with $0.1 \mathrm{~N}$ sodium hydroxide solution. Absorbance of diluted solution was measured at $304.0 \mathrm{~nm}$. The experimental drug content was calculated using calibration equation. The loading efficiency was calculated using formula:

$$
\% \text { loading efficiency }=\frac{\text { Experimental drug content }}{\text { Theoretical content }} \times 100
$$

The $\%$ yield of agglomerates was determined by weighing agglomerates after drying. The $\%$ yield of agglomerates was calculated using following equation.

$$
\% \text { Yield }=\frac{\text { total weight of agglomerates }}{\text { total weight of drug and polymer }} \times 100
$$

\section{Micromeritic parameters}

Micromeritic parameters like particle size analysis and flow properties of untreated drug and agglomerates were evaluated. The particle size analysis was performed by optical microscopy method. The size and size distribution of the 
agglomerates were determined by using eye piece micrometer which was calibrated using stage micrometer. The size of 50 arbitrarily selected agglomerates was considered and average diameter was calculated.

For the evaluation of flow property of the prepared agglomerates; angle of repose, Carr's index and Hausner's ratio were determined. Angle of repose was measured by using fixed funnel method. The agglomerates were allowed to flow through a funnel fixed at a constant height $(h)$ until the apex of the conical pile so formed touched the tip of funnel. Mean diameters (2r) of the pile of powder cone were measured and the angle of repose was calculated.

The Carr's index and Hausner's ratio were calculated from poured bulk density $\left(\rho_{0}\right)$ and tapped bulk density $\left(\rho_{t}\right)$. Electrolab tap density tester was utilized to determine poured and tapped bulk densities of untreated drug and agglomerates.

\section{Packability and compactability parameters}

Packability and compactibility parameters like $\boldsymbol{a}$ (compressibility), 1/b (cohesiveness) and $\boldsymbol{K}$ (Kuno's constant) were determined by Kawakita and Kuno's equations (Kawakita and Ludde, 1971; Denny, 2002). The values of 'a' and '1/b' was computed from the slope and intercept obtained from the linear plot of $n / C$ Vs n.

\section{Kawakita Equation: $\mathrm{n} / \mathrm{C}=1 /(\mathrm{ab})+\mathrm{n} / \mathrm{a}$ \\ Kuno Equation: $\ln \left(q_{t}-q_{n}\right)=-\mathrm{Kn}+\ln \left(q_{t}-q_{0}\right)$}

Where, $\mathrm{C}=\left(V_{0}-V_{n}\right) / \mathrm{V}_{0} ; n$ is number of tapping; $V_{0}$ is initial volume and $V_{n}$ is volume after $\mathrm{n}$ no. of tap; $q_{0}$ is initial density, $q_{n}$ is density at $\mathrm{n}$ tap and $q_{t}$ is density at infinite tap; $a, b$ and $K$ are the constants representing packability and compactibility of powder under mechanical force.

\section{Heckel plot analysis}

The compression behavior of pure drug crystals and prepared agglomerates were evaluated by Heckel plot analysis. Compacts of drug and agglomerates $(100 \pm 5 \mathrm{mg})$ were prepared using a 6-mm flat-faced punch at the constant compression speed at different pressures (10, 20, 30 and $40 \mathrm{MPa}$ ) (Maghsoodi et al., 2008). Dispersion of $1 \% \mathrm{w} / \mathrm{v}$ magnesium stearate in acetone was used to lubricate the punch and die. The compression characteristics of the agglomerates were expressed as parameters of Heckel equation (Heckel, 1961a; Heckel, 1961b).

$$
\ln [1 / \mathrm{E}]=\mathrm{KP}+\mathrm{A}
$$

Where, $E$ is the $\%$ porosity of the tablet, $P$ is the applied pressure, $K$ is the slope of Heckel plot; $P_{y}$, reciprocal of $K$, is the mean yield pressure. The constant $A$ expresses the densification at low pressure.

The value of E can be calculated using following equation.

$$
E=100\left(1-\frac{4 W}{P_{t} \pi D^{2} H}\right)
$$

Where, $W=$ weight of tablet mass, $P_{t}=$ true density, $H=$ thickness and $D=$ diameter

\section{Mechanical handling properties}

Elastic recovery of compacts was measured using the compacts prepared from pure drug crystals and agglomerates. After determination of thickness immediately after ejection $\left(\mathrm{H}_{\mathrm{c}}\right)$, the compacts were subjected for the $24 \mathrm{hr}$ relaxation and thickness of the compacts was measured again after relaxation $\left(\mathrm{H}_{\mathrm{e}}\right)$. Elastic recovery was calculated using the equation (Armstrong and Haines-Nutt, 1974).

$$
\% \mathrm{ER}=\left[\left(\mathrm{H}_{\mathrm{e}}-\mathrm{H}_{\mathrm{c}}\right) / \mathrm{H}_{\mathrm{c}}\right] \mathrm{X} 100
$$

After determination of elastic recovery, compacts prepared for Heckel plot analysis were used to determine tensile strength. For measurement of tensile strength, the force necessary to break compact (F) was measured (Rubinstein and Musikabhumma, 1978). The tensile strengths of the compacts were computed using following equation (Rundick et al., 1963; Fell and Newton, 1970).

$$
T=\frac{2 F}{\pi D t}
$$

Where, $\boldsymbol{D}$ and $\boldsymbol{t}$ are the diameter and thickness of the compacts respectively.

Mercury loaded cell method utilizing $10 \mathrm{ml}$ hypodermic glass syringe was used to determine crushing strength of the prepared agglomerates (Jarosz and Parrot, 1983). The agglomerate was positioned inside the syringe and the mercury was added at constant rate through hollow syringe tube until agglomerate broke. The total weight in $g$ of the tube with mercury, at the stage where agglomerate breaks was measured which gives the value of crushing strength of the agglomerate.

\section{Surface topography and sphericity determination}

Surface morphology was observed by photomicrographs of the drug and prepared agglomerates taken using optical microscope. To evaluate shape of prepared agglomerates, sphericity determination was performed. Photomicrographs of the agglomerates were taken and tracings of the enlarged photomicrographs were used for the measurement of area (A) and perimeter ( $\mathrm{P}^{\prime}$ ) of agglomerates. Sphericity determination of agglomerates was performed by calculating shape factor $(\mathrm{P})$ and circularity factor (S) from the area (A) and perimeter (P') of the agglomerates using following equations (Pawar et al., 2007).

Shape Factor $(\mathrm{P})=\mathrm{P}$ '/ $\mathrm{P}$ '

Where, $\mathrm{P} "=2 \pi(\mathrm{A} / \pi)^{1 / 2}$

Circularity Factor $(\mathrm{S})=\left(\mathrm{P}^{\prime}\right)^{2} / 4 \pi \mathrm{A}$ 


\section{Differential Scanning Calorimetry}

DSC was performed to evaluate drug-polymer compatibility. DSC thermograms of the pure drug crystals and prepared agglomerates were recorded using DSC-60 (Shimadzu, Tokyo, Japan) calorimeter to study the thermal behavior of drug and agglomerates. The instrument comprised of calorimeter (DSC 60), flow controller (FCL60), thermal analyzer (TA 60WS) and operating software (TA 60).

The samples (4-6 mg) were kept in hermetically sealed aluminum pans and heated in the temperature ranging from $45 \pm 1^{\circ}$ $\mathrm{C}$ to $300^{\circ} \mathrm{C}$ at a scanning rate of $10^{\circ} \mathrm{C} / \mathrm{min}$ in air atmosphere. Empty aluminum pan was used as a reference.

\section{Fourier Transform Infra-red (FT-IR) Spectroscopy}

To evaluate the drug-polymer compatibility and structural modification of drug during crystallization and agglomeration, FT-IR spectra of pure drug and prepared agglomerates were recorded. Infrared spectra of pure drug and agglomerates were performed using IR Spectrophotometer (FTIR 8400 Spectrophotometer, Shimadzu, Japan). The samples (approx. 2-3 mg) were homogeneously mixed with $\mathrm{KBr}$ and pressure was applied to compress them into disc or pellet. The IR Spectra were recorded by placing the pellets in light path.

\section{Powder X-ray Diffractometry}

PAN Analytical diffractometer system (Xpert pro PW 30-40/60) was used to record x-ray diffraction pattern for pure drug crystals and prepared agglomerates. The instrument comprised of a copper target and scintillation counter detector [45

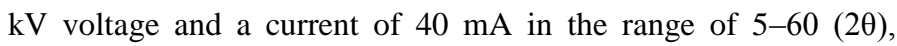
0.016 (step) and $30 \mathrm{~s}]$.

Non-rotating sample holder was used at room temperature as temperature of acquisition. The diffraction pattern was analyzed in $2 \theta$ range of $5^{\circ}$ to $60^{\circ}$.

\section{Scanning Electron Microscopy}

The shape and surface characteristics of pure drug crystals and agglomerates were examined by Scanning Electron Microscope (Make: ZEISS; Model No. : EVO-18-13-04). Sample kept in sputter coater (Make: Emitech, model no. SR7620) for 4 min and process current was $10 \mathrm{~mA}$. SEM photomicrographs were used to observe surface characteristics, agglomeration efficiency as well as packing of agglomerated crystals.

\section{In-vitro Dissolution Study}

In vitro dissolution studies for prepared agglomerates were performed using USP Apparatus I (Basket type) to assess the effect of agglomeration process and polymers on drug release. $1000 \mathrm{ml}$ of water (deaerated) was used as a dissolution medium at $37^{\circ} \pm 0.5^{\circ} \mathrm{C}$ and $50 \mathrm{RPM}$ (as per USP).

Samples of $5 \mathrm{ml}$ were withdrawn at a pre-determined time intervals $(0.5,1,2,3,4,5,6,7,8,9$ and 10 hours $)$ and each time the same amount of dissolution medium was added to replace the withdrawn samples. After suitable dilution with $0.1 \mathrm{~N} \mathrm{NaOH}$, samples were analyzed by UV-spectrophotometer at $304.0 \mathrm{~nm}$ and the cumulative $\%$ drug release was calculated.

\section{RESULTS AND DISCUSSION}

\section{Preparation of co-agglomerates}

The crystallo-co-agglomeration of drug with polymer was carried out using two solvent system including acetone as a good solvent and acetonitrile as a poor solvent. For preparation of agglomerates, speed (450 RPM), time of stirring ( $3 \mathrm{Hr}$ ), and other processing parameters were determined and fixed to optimum through preliminary trials. Mechanism of formation of agglomerates by crystallo-co-agglomeration involves crystallization of the drug by antisolvent and simultaneous agglomeration of crystals due to formation of liquid bridges by bridging liquid in presence of polymer. After filtration and drying, agglomerates were produced with homogeneous dispersion of crystallized drug throughout polymer matrix.

The $\%$ yield and \% loading efficiency of agglomerates were found satisfactory as depicted in Table 2. Results indicated that crystallization of drug and polymer was at the maximum amount to generate agglomerates without any significant loss of drug. Increased yield at higher polymer concentration was an indication of role of polymer in agglomeration of crystals by enhancement of formation of bridging and bonding between agglomerated crystals.

Table 2: $\%$ yield and \% loading efficiency of agglomerates $(\mathrm{n}=1)$.

\begin{tabular}{ccc} 
Table 2: \% yield and \% loading efficiency of agglomerates $(\mathrm{n}=1)$. \\
\hline Batch & \% Loading Efficiency & \% Yield \\
\hline ES1 & $82.18 \%$ & $73.25 \%$ \\
ES2 & $87.58 \%$ & $88.29 \%$ \\
ES3 & $86.70 \%$ & $90.67 \%$ \\
ES4 & $88.01 \%$ & $92.80 \%$ \\
ES5 & $87.87 \%$ & $92.50 \%$ \\
EL1 & $84.80 \%$ & $74.50 \%$ \\
EL2 & $87.14 \%$ & $89.71 \%$ \\
EL3 & $88.16 \%$ & $91.67 \%$ \\
EL4 & $87.72 \%$ & $92.80 \%$ \\
EL5 & $88.45 \%$ & $93.50 \%$ \\
\hline
\end{tabular}

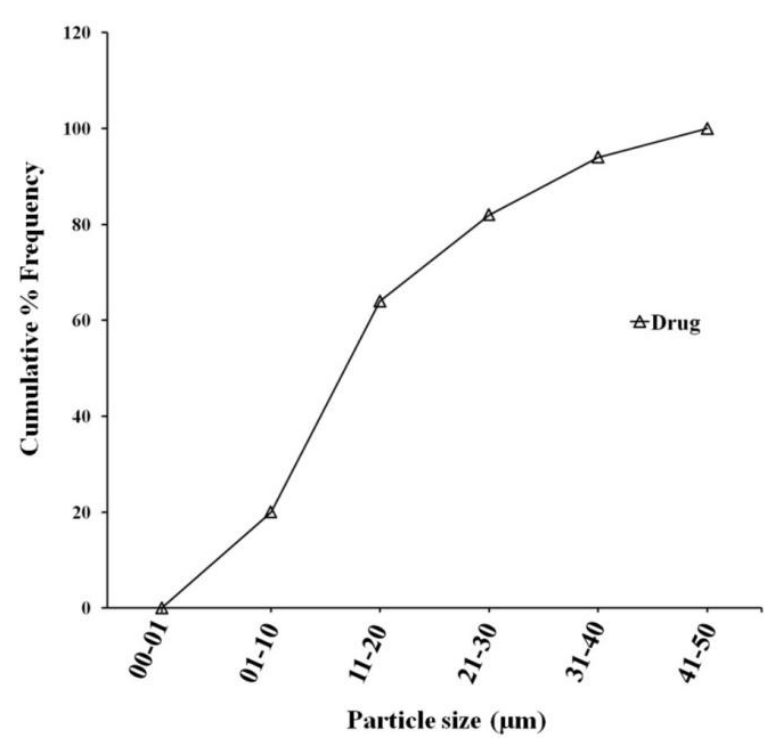

Fig. 1: Particle size distribution of pure drug crystals. 


\section{Micromeritic parameters}

Table 3 shows micromeritic parameters for pure drug crystals and prepared agglomerates. The results indicated substantial improvements in micromeritic properties of drug by agglomeration in presence of polymers. Particle size analysis was performed to determine mean diameter for each batch using optical microscopy. As revealed in Fig. 2 and Fig. 3, agglomerates formed were in the size range of 100 to $500 \mu \mathrm{m}$ with the mean size of around $300 \mu \mathrm{m}$ (Table 3). These findings indicated 10-20 folds rise in mean diameter of agglomerates compared to pure drug crystals which indicated growth of particles by simultaneous agglomeration after crystallization due to enhanced bonding and bridging formed in presence of polymers. Particle size was also affected by polymer concentration. As concentration of polymer increased, the particle size distribution shifted to higher size range indicating more agglomeration in presence of polymers.

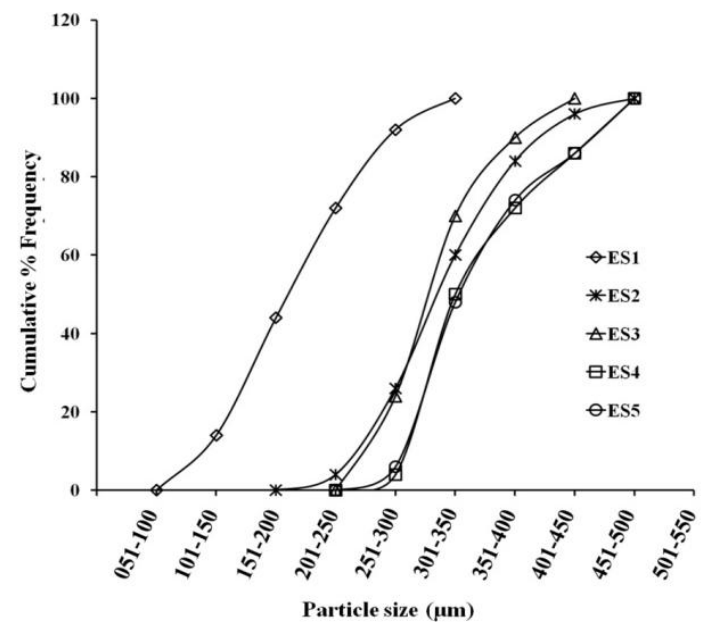

Fig. 2: Particle size distribution of agglomerates prepared with Eudragit RS100 (ES1 to ES5).

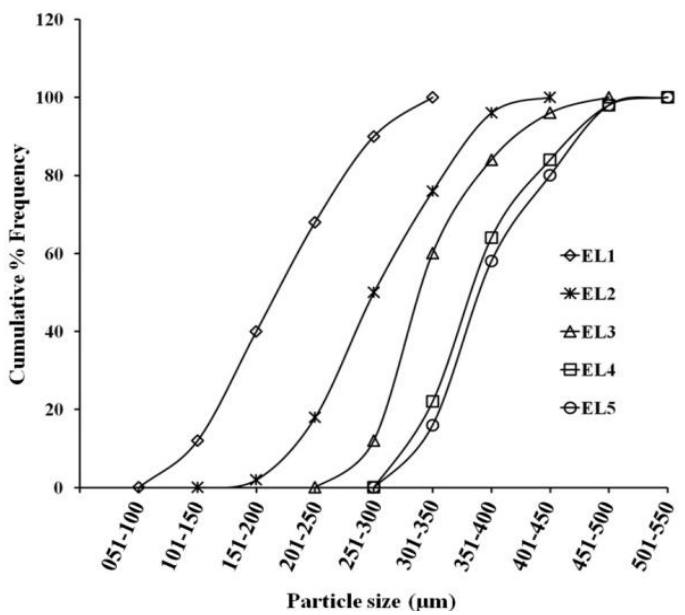

Fig. 3: Particle size distribution of agglomerates prepared with Eudragit RL100 (EL1 to EL5).

Improved flow property of agglomerates (Table 3) compared to pure drug crystals was revealed in results of angle of repose, Carr's index and Hausner's ratio. There was significant drop in Carr's index, Hausner's ratio and angle of repose of agglomerates compared to pure drug crystals. It indicated considerable improvement in flowability and packability of agglomerates. This can be attributed to formation of spherically agglomerated crystals with smooth surface by process of crystalloco-agglomeration in presence of polymers (Joshi et al., 2003).

Table 3: Micromeritic properties of drug and agglomerates.

\begin{tabular}{ccccc}
\hline Batch & $\begin{array}{c}\text { Diameter* } \\
(\mathbf{m m})\end{array}$ & $\begin{array}{c}\text { Angle of Repose } \\
(\mathbf{})\end{array}$ & $\begin{array}{c}\text { Carr's } \\
\text { Index }^{\#}(\mathbf{\%})\end{array}$ & $\begin{array}{c}\text { Hausner's } \\
\text { Ratio }^{\#}\end{array}$ \\
\hline Drug & $0.0195 \pm 0.010$ & $44.29 \pm 0.631$ & $33.69 \pm 1.64$ & $1.51 \pm 0.038$ \\
ES1 & $0.2160 \pm 0.053$ & $34.29 \pm 0.173$ & $24.83 \pm 0.76$ & $1.33 \pm 0.013$ \\
ES2 & $0.3416 \pm 0.058$ & $29.21 \pm 0.260$ & $20.91 \pm 0.81$ & $1.26 \pm 0.013$ \\
ES3 & $0.3331 \pm 0.048$ & $28.04 \pm 0.437$ & $20.39 \pm 1.04$ & $1.26 \pm 0.016$ \\
ES4 & $0.3683 \pm 0.057$ & $26.83 \pm 0.400$ & $20.25 \pm 0.80$ & $1.25 \pm 0.013$ \\
ES5 & $0.3691 \pm 0.056$ & $27.08 \pm 0.231$ & $19.33 \pm 1.15$ & $1.24 \pm 0.018$ \\
EL1 & $0.2216 \pm 0.055$ & $34.59 \pm 0.305$ & $26.31 \pm 1.02$ & $1.36 \pm 0.019$ \\
EL2 & $0.3056 \pm 0.057$ & $28.39 \pm 0.215$ & $23.38 \pm 0.26$ & $1.31 \pm 0.004$ \\
EL3 & $0.3512 \pm 0.049$ & $26.83 \pm 0.296$ & $21.86 \pm 0.25$ & $1.28 \pm 0.004$ \\
EL4 & $0.3931 \pm 0.050$ & $25.64 \pm 0.180$ & $20.39 \pm 1.04$ & $1.26 \pm 0.016$ \\
EL5 & $0.4029 \pm 0.048$ & $24.77 \pm 0.165$ & $19.61 \pm 0.38$ & $1.24 \pm 0.006$ \\
\hline
\end{tabular}

*Results are mean \pm SD of $n=50$ particles;

\# Results are mean $\pm \mathrm{SD}$ of $\mathrm{n}=3$ observations.

\section{Packability and compactability parameters}

Table 4 shows smaller values for parameter $a$ (compressibility) and parameter $1 / b$ (cohesiveness) for agglomerates than that of the pure drug crystals calculated by Kawakita equation. This indicated of notable improvement in packing and compaction properties of agglomerates compared to pure drug crystals. These results were also supported by increased values of $K$ (Kuno's constant) for agglomerates compared to pure drug crystals.

Table 4: Packability parameters of drug and agglomerates $(n=1)$.

\begin{tabular}{cccc}
\hline \multirow{2}{*}{ Batch } & \multicolumn{2}{c}{ Kawakita's Constants } & $\begin{array}{c}\text { Kuno's } \\
\text { Constants }\end{array}$ \\
\cline { 2 - 4 } & $\mathbf{A}$ & $\mathbf{1 / b}$ & $\mathbf{K}$ \\
\hline Drug & 0.3590 & 3.7343 & 0.1001 \\
ES1 & 0.2474 & 2.9592 & 0.0924 \\
ES2 & 0.2201 & 1.9028 & 0.1129 \\
ES3 & 0.1832 & 1.7328 & 0.1353 \\
ES4 & 0.2006 & 2.1619 & 0.1056 \\
ES5 & 0.2031 & 1.5231 & 0.1435 \\
EL1 & 0.2786 & 1.4011 & 0.1297 \\
EL2 & 0.2395 & 1.6997 & 0.1192 \\
EL3 & 0.2197 & 1.8623 & 0.1125 \\
EL4 & 0.2046 & 2.1619 & 0.1053 \\
EL5 & 0.1992 & 1.5232 & 0.1439 \\
\hline
\end{tabular}

These can also be supported by results in Table 4 showing higher values of K (Kuno's constant) for agglomerates compared to that of pure drug crystals, calculated using Kuno's equation. Results also indicated improved rate of packing processes for agglomerates than that of pure drug crystals. The improvements in packing and compression properties could be attributed to formation of dense particles with increased particle size and sphericity by crystallo-co-agglomeration in presence of polymers (Sarfaraz et al., 2011).

\section{Heckel plot analysis}

Density of compacts formed when maximum pressure (60 $\mathrm{MPa})$ was applied on the powder/agglomerates was considered 
as the true density (Barot et al., 2010). The parameters of Heckel plot for pure drug crystals and agglomerates are depicted in Table 5. As shown in Table 5, agglomerates possessed improved packing and compression properties compared to pure drug crystals. The linearity in the Heckel plot (Fig. 4 and Fig. 5) was a suggestion of plastic deformation. In the Heckel plot equation, " $\mathrm{K}$ " is an indication of plastic behavior of the material (Fig. 4 and Fig. 5). Bigger the value of " $\mathrm{K}$ ", better is the plasticity in material.

Table 5: Heckel Plot Parameters $(n=1)$.

\begin{tabular}{cccc}
\hline \multirow{2}{*}{ Batch } & \multicolumn{2}{c}{ Heckel Plot constants } & $\begin{array}{c}\text { Yield } \\
\text { Strength }\left(\boldsymbol{\sigma}_{\mathbf{o}}\right)\end{array}$ \\
\cline { 2 - 3 } & Constant $\left(\mathbf{A}^{*}\right)$ & Yield Pressure $\left(\mathbf{P}_{\mathbf{y}}\right)$ & 8.73 \\
Drug & 0.72 & 26.18 & 5.69 \\
ES1 & 0.71 & 17.06 & 5.01 \\
ES2 & 0.69 & 15.02 & 4.76 \\
ES3 & 0.55 & 14.27 & 4.69 \\
ES4 & 0.52 & 14.06 & 4.42 \\
ES5 & 0.48 & 13.26 & 5.88 \\
EL1 & 0.68 & 17.64 & 4.85 \\
EL2 & 0.54 & 14.56 & 4.78 \\
EL3 & 0.46 & 14.33 & 4.38 \\
EL4 & 0.41 & 13.14 & 4.08 \\
EL5 & 0.33 & 12.24 & \\
\hline
\end{tabular}

* indicates densification at low pressure

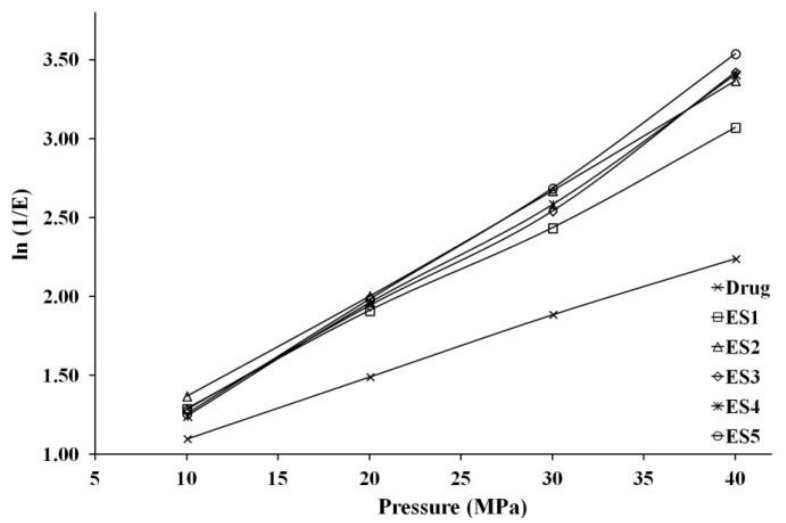

Fig. 4: Heckel plots of drug $(\times)$ and agglomerates prepared with Eudragit RS 100 (ES1 to ES5).

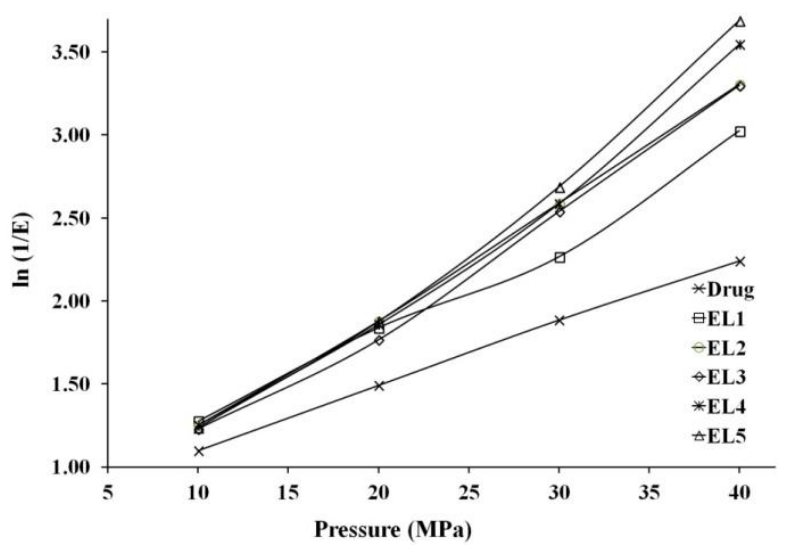

Fig. 5: Heckel plots of drug $(x)$ and agglomerates prepared with Eudragit RL 100 (EL1 to EL5).

Moreover, results of Heckel plot analysis showed smaller values of "A" for agglomerates compared to pure drug crystals. The results are an indication of lower compression pressure requirements for obtaining closest packing of agglomerated crystals as well as improved densification (Di Martino et al., 2000). Lower value of yield strength in case of agglomerates prepared in presence of polymer indicated a little resistance to compression pressure and easy compaction. Thus, findings of Heckel plot analysis suggested utilization of agglomerates for direct compression as they generate new surface by easily cracking and undergo plastic deformation under compression (Kawashima et al., 2003).

\section{Mechanical handling properties}

Improvements in mechanical handling parameters were revealed in results depicted in Table 6. The values of crushing strength for agglomerates were higher (Table 6) indicating excellent strength. It is also a sign of higher bonding property. This could be accredited to increased bridging and bonding during agglomeration of crystals with polymers. As revealed in Table 6, crushing strengths of agglomerates were directly related to polymer concentration which indicated role of polymers in formation of strong interpaticulate forces between agglomerated crystals due to enhanced bridging and bonding. Good mechanical strength of agglomerates might be attributed to increased cohesive interaction resulting in enhanced binding and close packing between agglomerated crystals (Pawar et al., 2007).

Table 6: Mechanical handling parameters and Elastic recovery.

\begin{tabular}{cccc} 
Batch & $\begin{array}{c}\text { Crushing } \\
\text { Strength* } \\
(\mathbf{g m})\end{array}$ & $\begin{array}{c}\text { Tensile } \\
\text { Strength* } \\
\mathbf{( k g}^{\text {(cm }} \mathbf{~}\end{array}$ & $\begin{array}{c}\text { Elastic Recovery* } \\
\mathbf{( \% )}\end{array}$ \\
\hline Drug & -- & $11.619 \pm 1.030$ & $3.266 \pm 0.703$ \\
ES1 & $15.187 \pm 0.811$ & $16.126 \pm 0.475$ & $1.231 \pm 0.205$ \\
ES2 & $27.183 \pm 0.883$ & $17.711 \pm 0.452$ & $1.104 \pm 0.117$ \\
ES3 & $35.043 \pm 1.512$ & $18.533 \pm 0.241$ & $0.902 \pm 0.121$ \\
ES4 & $47.337 \pm 0.680$ & $18.534 \pm 0.548$ & $0.764 \pm 0.122$ \\
ES5 & $54.250 \pm 1.316$ & $19.510 \pm 0.496$ & $0.698 \pm 0.120$ \\
EL1 & $15.500 \pm 0.719$ & $14.710 \pm 0.521$ & $1.300 \pm 0.119$ \\
EL2 & $29.953 \pm 1.165$ & $17.423 \pm 0.500$ & $1.173 \pm 0.118$ \\
EL3 & $37.247 \pm 1.166$ & $18.011 \pm 0.261$ & $0.898 \pm 0.121$ \\
EL4 & $50.143 \pm 1.015$ & $18.124 \pm 1.092$ & $0.834 \pm 0.002$ \\
EL5 & $56.160 \pm 1.290$ & $19.165 \pm 0.396$ & $0.696 \pm 0.122$ \\
\hline
\end{tabular}

*Results are mean \pm SD of $n=3$ observations.

Higher values of tensile strength of agglomerates compared to pure drug crystals indicated improvement in mechanical handling properties of agglomerates (Table 6). High tensile strength of compacts of agglomerates compared to that of pure drug crystals indicated strong interparticulate bonding generated between agglomerated crystals produced by crystalloco-agglomeration in presence of polymers (Maghsoodi et al., 2007).

Smaller values of elastic recoveries in the case of agglomerates indicated good agglomeration between particles. The results also indicated that agglomerates could easily rupture to generate new surface which might be attributed to plastic deformation (Kawashima et al., 2003). Decreased elastic recoveries with increase in polymer concentration indicated role of polymers in plastic deformation and compaction of agglomerates 
prepared by crystallo-co-agglomeration. These also indicated higher bonding produced by polymers.

\section{Surface topography and sphericity determination}

As shown in photomicrographs (Fig. 6), agglomerates showed remarkable enhancement in surface characteristics and sphericity compared to pure drug crystals. Pure drug crystals possess irregular shape with more quantity of fines resulting in more electrostatic charges which eventually lead to vastly poor flow and compaction properties (Kumar et al., 2008).

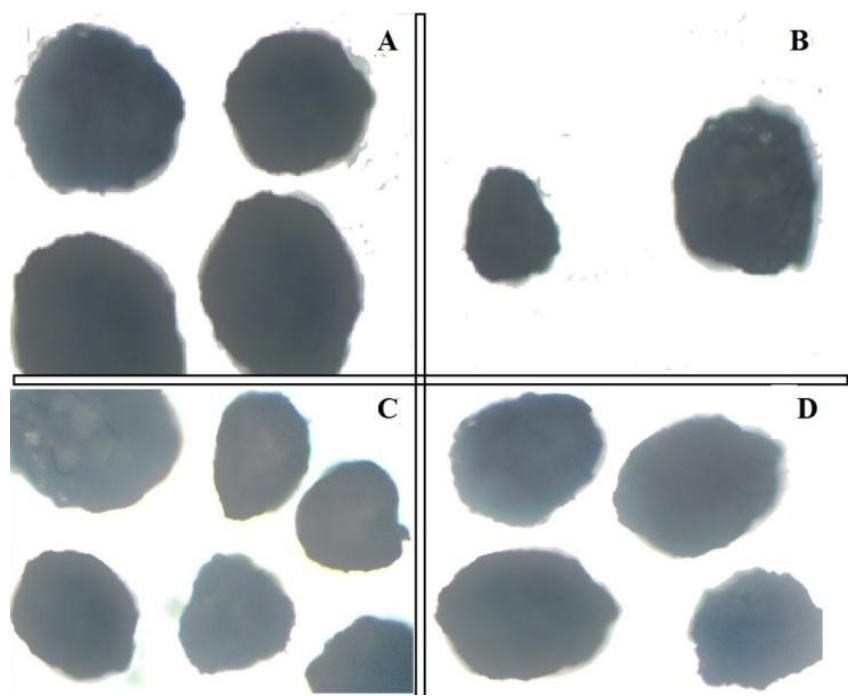

Fig. 6: Photomicrographs of agglomerates prepared with Eudragit RS100 (A and B); and agglomerates prepared with Eudragit RL100 (C and D).

Table 7 shows values of shape and circularity factors for agglomerates. The results obtained in the shape and circularity factors were close to unity (1) showed that the agglomerates possess nearly spherical shape. Improved results of flow and compression properties can be accredited to the shape towards sphericity.

Table 7: Sphericity Parameters of agglomerates.

\begin{tabular}{ccc}
\hline Batch & Shape Factor* $(\mathbf{P})$ & Circulatory Factor* $(\mathbf{S})$ \\
\hline ES1 & $0.8375 \pm 0.0338$ & $1.4310 \pm 0.1190$ \\
ES2 & $0.9664 \pm 0.0620$ & $1.0799 \pm 0.1269$ \\
ES3 & $0.9937 \pm 0.0615$ & $1.0214 \pm 0.1259$ \\
ES4 & $0.9870 \pm 0.0369$ & $1.0297 \pm 0.0741$ \\
ES5 & $1.0109 \pm 0.0165$ & $0.9792 \pm 0.0323$ \\
EL1 & $0.8551 \pm 0.0099$ & $1.3682 \pm 0.0311$ \\
EL2 & $0.9894 \pm 0.0260$ & $1.0232 \pm 0.0520$ \\
EL3 & $0.9932 \pm 0.0353$ & $1.0164 \pm 0.0689$ \\
EL4 & $0.9890 \pm 0.0225$ & $1.0234 \pm 0.0451$ \\
EL5 & $0.9974 \pm 0.0279$ & $1.0070 \pm 0.0564$ \\
\hline
\end{tabular}

*Results are Mean \pm SD of $\mathbf{n}=\mathbf{4}$ particles.

\section{Differential Scanning Calorimetry}

As revealed in Fig. 7, sharp endothermic peaks were observed in DSC thermogram of pure drug crystals and agglomerates indicating uniformity in crystalline structure. Peaks were observed at $146.88{ }^{\circ} \mathrm{C}, 147.09{ }^{\circ} \mathrm{C}$ and $148.13{ }^{\circ} \mathrm{C}$ for untreated drug, agglomerates prepared with Eudragit RS100 and agglomerates prepared with Eudragit RL100 respectively indicating no significant difference in melting points. The results indicated absence of drug-polymer interaction as well as material was not affected by process of crystallo-co-agglomeration in presence of polymer.

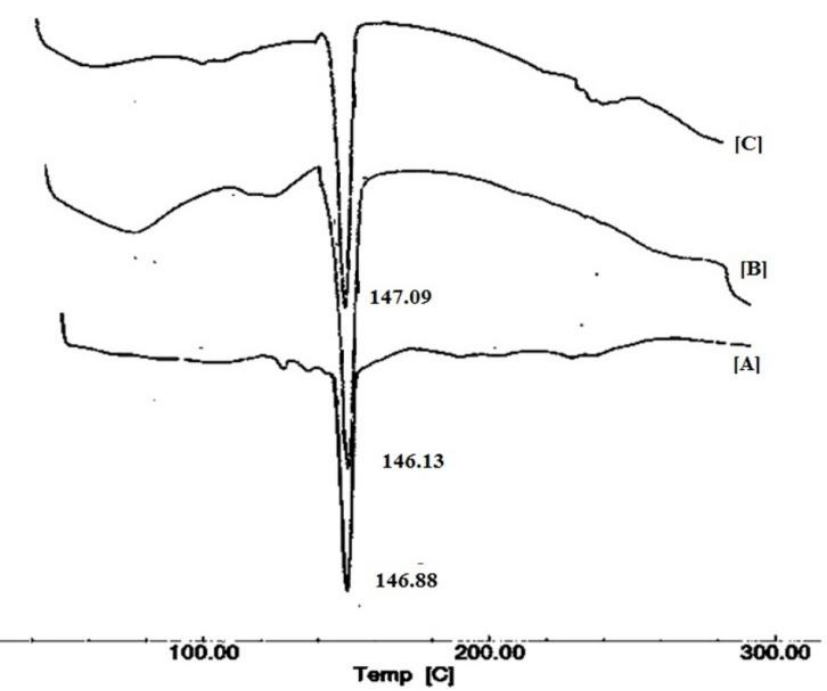

Fig. 7: DSC thermogram of drug $[\mathrm{A}]$ and agglomerates prepared with Eudragit RS100 [B] and Eudragit RL100 [C].

\section{Fourier Transform Infra-red (FT-IR) Spectroscopy}

FT-IR spectra of agglomerated crystals showed almost all peaks of the drug (Fig. 8). FTIR spectra of pure drug and agglomerates shows the peaks corresponding to functional groups at $1155 \mathrm{~cm}^{-1}$ (C-O stretching), $1215 \mathrm{~cm}^{-1},(\mathrm{C}-\mathrm{N}), 1582 \mathrm{~cm}^{-1}(\mathrm{C}=\mathrm{O}$ stretching), $3400 \mathrm{~cm}^{-1}$ (very broad, O-H stretch), $966 \mathrm{~cm}^{-1}$ (aryl-F), indicating no molecular change in the drug during process of crystallo-co-agglomeration in presence of polymers as well as absence of drug-polymer interaction.

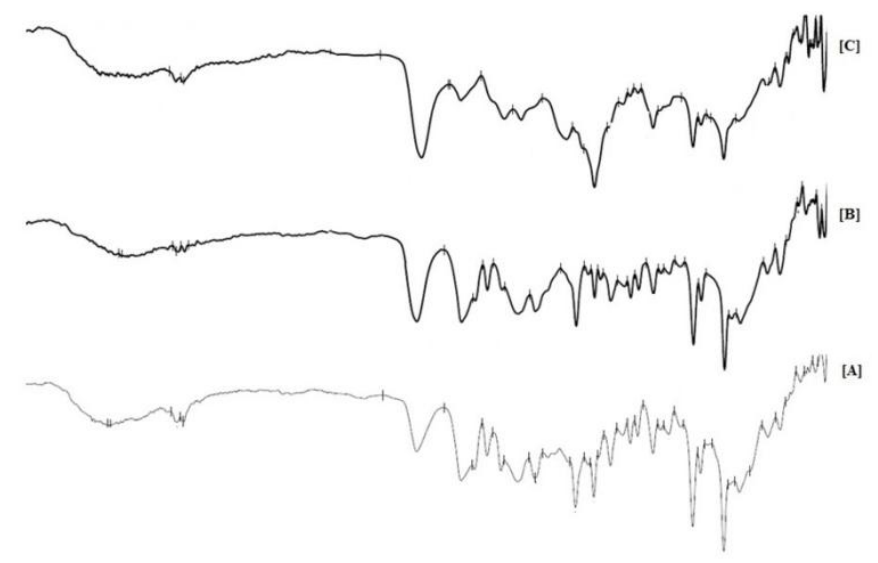

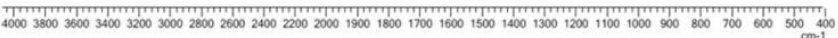

Fig. 8: FTIR spectra of drug [A] and agglomerates prepared with Eudragit RS100 [B] and Eudragit RL100 [C].

\section{X-ray diffractometry}

As shown in XRD spectra of pure drug crystals and agglomerates, the characteristic diffraction peaks of drug were 
detectable in the XRD spectra of agglomerates (Fig. 9). These findings indicated that particles crystallized in presence of polymers did not undergo structural or polymorphic alterations (Gupta et al., 2007). Although, identical peak intensities were there for the drug as well as agglomerates, change in the relative intensities of their peaks may be due to differences in the crystallinity of the drug and agglomerates (Jbilou et al., 1999). To identify the presence of polymers is very difficult as they may have amorphous structure and therefore no sharp peaks were appeared at particular $2 \theta$, due probably to lower crystallinity of the polymers (Maghsoodi et al., 2008).

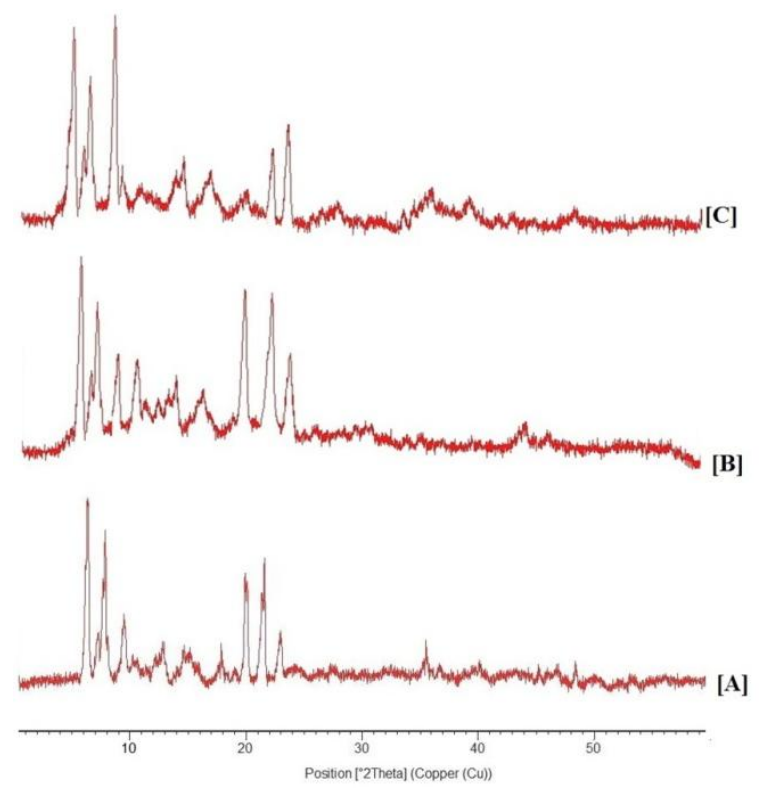

Fig. 9: $\mathrm{XRD}$ spectra of drug $[\mathrm{A}]$ and agglomerates prepared with Eudragit RS100 [B] and Eudragit RL100 [C]

\section{Scanning Electron Microscopy}

As shown in the SEM photographs of the pure drug crystals (Fig. 10), it has very fine crystals with irregular shape which possess poor flow and compaction properties. As shown in Fig. 11 and Fig. 12, agglomerates prepared with polymers possessed good agglomeration with smooth surface. The agglomerates prepared with polymers have improved flowability and compactibility as compared to pure drug crystals which can be attributed to improved agglomeration of crystals as well as smooth surface.

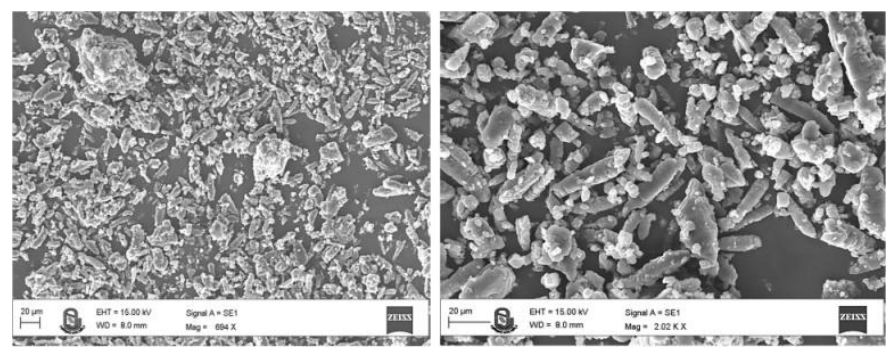

Fig. 10: SEM photographs of pure drug crystals.
As revealed in the Fig. 11 and Fig. 12, agglomerates were generated with uniform packing and well developed edges with spherical shape. The results also indicated that crystals were agglomerated in presence of polymers to form compacted spherical agglomerates. Moreover, agglomeration was more efficient when polymers were used. This can also be correlated with improved results of flow and compaction parameters as well as results of shape and circularity factors.

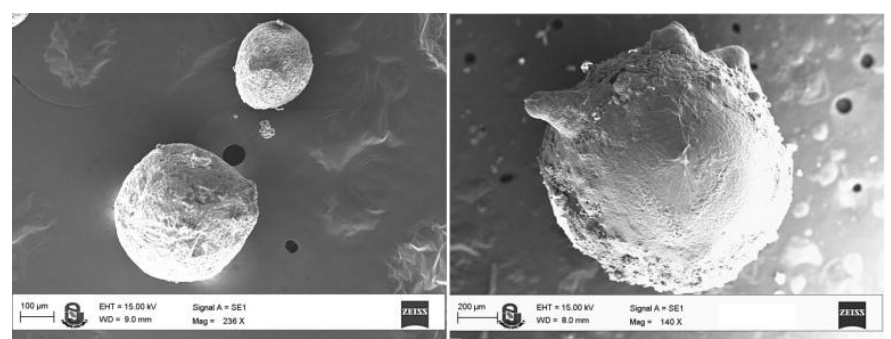

Fig. 11: SEM photographs of agglomerates prepared with Eudragit RS100.

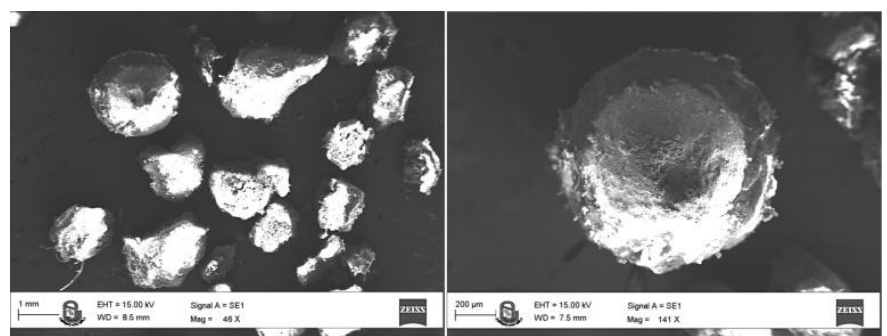

Fig. 12: SEM photographs of agglomerates prepared with Eudragit RL100.

\section{In-vitro dissolution study}

As shown in Fig. 13 and Fig. 14, the rate of dissolution of untreated drug is fast. Short biological half life requires frequent dosing to maintain plasma concentration. The agglomerates prepared in presence of polymer have controlled rate of drug dissolution depending upon type and concentration.

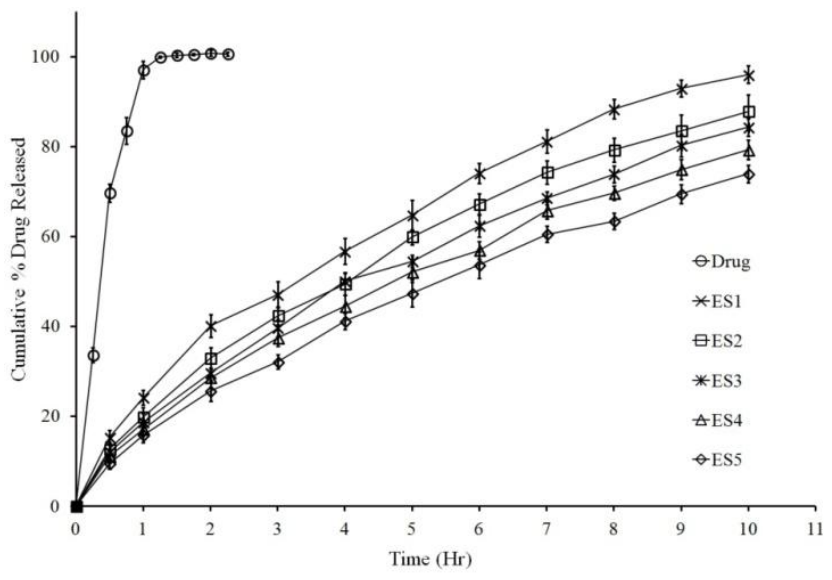

Fig. 13: Dissolution profile of Drug $(\mathrm{O})$ and agglomerates prepared with Eudragit RS100 (ES1 to ES5).

Types of polymer have profound effect on dissolution rate of drug. Amongst Eudragit polymers, Eudragit RS100 has more retardant effect compared to Eudragit RL100 which may be 
due to more number of quaternary ammonium groups present in Eudragit RL100 making it more permeable.

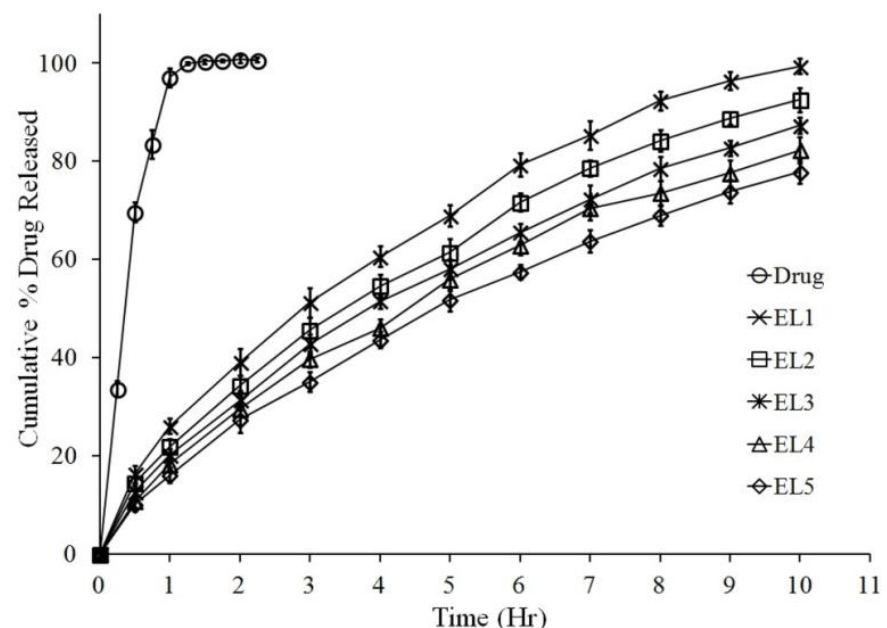

Fig. 14: Dissolution profile of Drug $(\mathrm{O})$ and agglomerates prepared with Eudragit RL100 (EL1 to EL5).

Drug release rate is inversely proportional to the polymer concentration. As concentration of polymer increased, retardant effect of polymer also increased resulting in prolonged drug release for extended period of time depending on polymer concentration.

\section{CONCLUSION}

Crystallo-co-agglomeration has been effectively utilized as agglomeration technique to prepare sustained release agglomerates of fluvastatin sodium with polymers. Agglomerates obtained with improved micromeritic, mechanical and compression properties. Spherical agglomerates have increased particle size with improved flow properties and packability indicating reduced interparticulate friction. Agglomerates also possessed sufficient mechanical strength as well as improved compaction and compression properties due to remarkable fragmentation and increased tensile strength indicating utilization of agglomerates for direct compression. Sphericity of agglomerates can be revealed in photomicrographs, SEM photos and results of shape and circularity factors.

In-vitro dissolution study revealed sustained release of drug over an extended period of time which was dependent on polymer concentration. DSC, FTIR and XRD results indicated absence of drug -polymer interaction. Thus, this simple, reliable and economic technique enables us to obtain directly compressible sustained release agglomerates in combination with polymers.

\section{Financial support and sponsorship: Nil.}

Conflict of interest: The authors declare no conflict of interest.

\section{REFERENCES}

Armstrong N, Haines-Nutt R. Elastic recovery and surface area changes in compacted powder systems. Powder Technol, 1974; 9:287-290.

Barot B, Parejiya P, Patel T, Parikh R, Gohel M. Development of directly compressible metformin hydrochloride by the spray-drying technique. Acta Pharm, 2010; 60:165-175.

Chien Y, Lin S. Drug Delivery: Controlled Release. In: James Swarbrick, Editor. Encyclopedia of Pharmaceutical Technology. Vol. II, 3rd ed. New York, Informa Healthcare USA, Inc.; p. 1082-1103.

Denny P. Compaction equations: a comparision of the Heckel and Kawakita equations. Powder Technol, 2002; 127:162-172.

Di Martino P, Di Cristofaro R, Barthelemy C, Joiris E, Palmieri Filippo G, Sante M. Improved compression properties of propyphenazone spherical crystals. Int J Pharm, 2000; 197:95-106.

Fell J, Newton J. Determination of tablet strength by the diametral compression test. J Pharm Sci, 1970; 59:688-691.

Gadekar S, Kale V, Abhishek C, Keshav M. Development of extended release formulation for 5-amino salicylic acid using Coagglomeration technique. Der Pharma Let, 2011; 3:212-219.

Garala K, Patel J, Patel A, Raval M, Dharamsi A. Influence of excipients and processing conditions on the development of agglomerates of racecadotril by crystallo-coagglomeration. Int J Pharm Investig, 2012; 2:189-200

Gupta S, Munjal T, Bhatia P, Inderjeet K. Fabrication and evaluation of fluvastatin sodium loaded sustained release microspheres using polymer blends. Int J Pharm Pharm Sci, 2014; 6:365-371.

Gupta V, Srinivas M, Patel M, Jani G. Spherical crystals of celecoxib to improve solubility, dissolution rate and micromeritic properties. Acta Pharm, 2007; 57:173-184.

Heckel R. Density-pressure relationships in powder compaction. Trans Metal Soc AIME, 1961a; 221:671-675.

Heckel R. An analysis of powder compaction phenomena. Trans Metal Soc AIME, 1961b; 221:1001-1008.

Jadhav N, Paradkar A, Pawar A. Effect of drug content and agglomerate size on tabletability and drug release characteristics of bromhexine hydrochloride-talc agglomerates prepared by crystallo-coagglomeration. Act Pharm, 2010; 60:25-38.

Jadhav N, Pawar A, Paradkar A. Design and evaluation of deformable talc agglomerates prepared by crystallo-co-agglomeration technique for generating heterogenous matrix. AAPS PharmSciTech, 2007; 8:E61-E67.

Jarosz P, Parrot E. Comparison of granule strength and tablet strength. J Pharm Sci, 1983; 72:530-535.

Jbilou M, Ettabia A, Guyot-Hermann A, Guyot J. Ibuprofen agglomerates preparation by phase separation. Drug Dev Ind Pharm, 1999; 25:297-305

Joshi A, Shah S, Mishra A. Preparation and evaluation of directly compressible form of rifampicin and ibuprofen. Ind J Pharm Sci, 2003; 65:232-238

Kadam S, Mahadik K, Paradkar A. A process for making agglomerates for use as or in a drug delivery system. Indian patent 183 481 (1997).

Kawakita K, Ludde K. Some considerations on powder compression equations. Powder Technol, 1971; 4:61-68.

Kawashima Y, Imai M, Takeuchi H, Yamamoto H, Kamiya K. Improved flowability and compactibility of spherically agglomerated crystals of ascorbic acid for direct tabletting designed by spherical crystallization process. Powder Technol 2003; 130:283-289.

Kumar S, Chawla G, Bansal A. Spherical crystallization of mebendazole to improve processability. Pharm Dev Tech, 2008; 13:559568.

Maghsoodi M, Hassan-Zadeh D, Barzegar-Jalali M, Nokhodchi A, Martin G. Improved compaction and packing properties of naproxen agglomerated crystals obtained by spherical crystallization technique. Drug Dev Ind Pharm, 2007; 33:1216-1224.

Maghsoodi M, Tajalli Bakhsh A. Evaluation of physicomechanical properties of drug-excipients agglomerates obtained by crystallization. Pharm Dev Tech, 2011; 16:243-249. 
Maghsoodi M, Taghizadeh O, Martin GP, Nokhodchi A. Particle design of naproxen-disintegrant agglomerates for direct compression by a crystallo-co-agglomeration technique. Int J Pharm, $2008 ; 351: 45-54$.

Maghsoodi M, Yari Z. Effect of drying phase on the agglomerates prepared by spherical crystallization. Iran J Pharm Res, 2015; 14:51-57.

Mahajan H, Deore B, Deore U. Development and characterization of sustained release microspheres by quasi emulsion solvent diffusion method. Int J ChemTech Res, 2009; 1:634-642.

Ozyazici M, Sevgi F, Pekcetin C, Sarpas B, Sayin S. Sustained release spherical agglomerates of polymethacrylates containing mefenamic acid: in vitro release, micromeritic properties and histological studies. Pharm Dev Tech, 2012; 17:483-893.

Pawar A, Paradkar A, Kadam S, Mahadik K. Crystallo-coagglomeration: a novel process to obtain ibuprofen-paracetamol agglomerates. AAPS PharmSciTech, 2004; 5:57-64.

Pawar A, Paradkar A, Kadam S, Mahadik K. Effect of polymers on crystallo-co-agglomeration of ibuprofen-paracetamol: factorial design. Ind J Pharm Sci, 2007; 69:658-664.

Raval M, Sorathiya K, Chauhan N, Patel J, Parikh R, Sheth N. Influence of polymers/excipients on development of agglomerated crystals of secnidazole by crystalloco- agglomeration technique to improve processability. Drug Dev Ind Pharm, 2013; 39:437-446.

Rubinstein M, Musikabhumma P. A universal friability test for tablet granules. Pharm Acta Helv, 1978; 53:125-132.

Rundick A, Hunter A, Holden F. An analysis of the diametral compression test. Mater Res Stand, 1963; 3:283-289.
Saini N, Saini G. Formulation and characterization of fluvastatin sodium loaded microspheres. Int J Pharm Life Sci, 2016; 7:5034-5041.

Sarfaraz M, Khan K, Doddayya H, Reddy SR, Udupi RH. Particle design of aceclofenac-disintegrant agglomerates for direct compression by crystallo-co-agglomeration technique. Asian J Pharm Tech, 2011; 1:40-48.

Venkatesh D, Roopa K, Sajal K, Geetha L, Santha K, Divakar G. Formulation and evaluation of microspheres containing fluvastatin sodium. Int J Drug Dev Res, 2012; 4:306-314.

Williams D, Lemke T. Foye's Principles of Medicinal Chemistry, fifth ed., Lippincott Williams \& Wilkins, A Wolters Kluwer Company, Philadelphia, 2002, p. 580-600.

\section{How to cite this article:}

Shah D, Sorathia K. Design and evaluation of sustained release spherical agglomerates of Fluvastatin sodium by crystallo-coagglomeration. J App Pharm Sci, 2017; 7 (09): 099-108. 